\title{
Cultural Sustainability between Traditional and Contemporary Omani Residences - A Comparative Case Study
}

\author{
By Soheir M. Hegazy ${ }^{1}$
}

\begin{abstract}
In the twentieth century, majority of the countries were tempted to adopt up-to-date building designs. The fashionable designs neglected the context of its environment, cultural values, social performance and even economic perspective and sustainability. The year 1970 represented the starting point of shifting Sultanate of Oman from being a closed, listless society to a modern state. The aim to build a modern society did not compel this historic country to neglect its heritage or cultural principles. The main hypothesis of this research is that Oman has wonderful experience in cultural sustainability between traditional and contemporary residences. This research aims to derive lessons and principles from such successful models of Oman. This work is dependent on a theoretical foundation of previous related references, analysis, interpretation and a comparative case study. Some tools used were interviews, analytical site visits and questionnaire. The research succeeded in revealing the procedure used by Oman to keep the identity and continuity of its buildings. The wonderful response of both traditional and contemporary Omani residence to the surrounding, cultural aspects, and human needs is shown. This research provides a current example to researchers, students, designers and decision makers of a humanely oriented house design.
\end{abstract}

Keywords: Traditional Omani architecture; Contemporary Omani residences, , cultural sustainability,

House Moqham, Bait el Dalalil

\section{Introduction}

The Sultanate of Oman is a country in South West Asia on the Arabian Sea with a current population of 2.774 million according to 2010 census. (www.muscatdaily.com). In spite of Oman's dramatic developments over the last four decades following an oil-producing reaction, Oman is one of the few countries in the Arab world that has kept its traditional culture in spite of globalization and modernization. Recently, many calls were raised to re-evaluate

the relationship between modern architecture and its surroundings, inhabitants and its equilibrium with the universe and the earth.

The traditional architecture of Oman was shaped by the forces of natural environment and culture that affected lifestyle, mood, faith and identity-(Al Zubair, 2013). This paper will focus on the cultural aspects which influenced Omani architecture and still is one of the vital parameters of sustainability. According to Sir Geoffrey Jellicos; "Architecture is to make us know and remember who we are" (Al Zubair, 2013) One life fact is that there can be as many different cultures as there are different communities, and each community has its own beliefs, values, and traditions. Accordingly, enabling each community to find methodologies that preserve each ones cultural sustainability. This a cumulative effect when the world is viewed as one global community consisting of many local ones. Moreover, special efforts to preserve traditionally built landmarks that promot a sense of place, are crucial aspects of cultural sustainability. Accordingly, maintaining 
the historic monuments offer environmental advantages too because not demolishing the structures means building materials are not disposed as waste in landfill (Scammon, www.academia.edu )

This paper aims to recognize the successful Omani model for keeping cultural sustainability between traditional and contemporary Omani architecture as a paradigm to other states, researches, students, and design makers. It must be considered that the paper will limit the research to Omani residences. "The most interactive type of Omani buildings with the cultural and environmental constraints" (Abdul Majid, 2013) The paper also examines the sustainable design parameters of traditional and contemporary residences and current behavior and attitude of occupants to illuminate future studies.

This work is dependent on a theoretical foundation of previous related references, analysis, interpretation and cross comparative case studies. Some tools were used like interviews, analytical site analysis, and a questionnaire. The research succeeded in revealing the procedure used by Oman to keep sustainability between its historic and contemporary structures. The wonderful response of both traditional and contemporary Omani architecture to the environmental and cultural needs is deduced. Nevertheless, the Omani people's attitude concerning the cultural sustainability is also revealed.

The first point clarifies the response of traditional Omani residence to both cultural and environmental constraints. Then, the state policy in adopting contemporary and traditional Omani architecture through many decisive regulations and legislations is discussed. The current Omani people's attitude to house design is illuminated through a questionnaire distributed by architecture consultants. Results subsequently, Cultural continuity is revealed through cross case study analysis of three residence examples that were erected in a time frame of three centuries. Finally, the conclusion and recommendations are deduced.

\section{Literature Review}

A brief literature review about the main issue of this work; traditional Arabic house, Omani architecture and cultural sustainability are laid out in this section.

Hassan Fathy discussed the importance of keeping balance between any structure and the environment considering the climate, the material and the surroundings (Fathy, 1969) Basim Hakim discussed the traditional Islamic architecture to drive principles and lessons from the past to be used today in many publications (Hakim, 1986) (Hakim, 2008) (Hakim, 2009) AbdelMoniem El Shorbagy classified the vocabulary of traditional Islamic Arab house in detail (El Shorbagy, 2010) Khaled Azzam discussed how the religion of Islam affected the daily life of Muslim and its effects on art and architecture. He clarified that using the traditional forms has an inherent symbolic language that stay alive (seen in Adam, 2008) The Omani architecture was discussed in many publications; some books went through ancient Oman till the present discussing all the types of architecture in all districts and the government's effort in keeping the continuity between the traditional and contemporary architecture and conservation (Damluji, 1999) (Bamdyopadhyay, 2001) (Biancifiori, 1994) (Kit, 2002) (Al Zubair, 2013) Most of the publications that discussed the Omani house clarified the effect of the climate with reference to the cultural effect (Al Lawati, 2005) (Abdul Majid Etal, 2003) The applications of traditional ideas in contemporary buildings was also discussed (Al-Hinai etal, 1993) (Taylor etal, 2009) Social and cultural sustainability was discussed at the level of urban planning in many editions (Axelsson etal, 2013) (Elnokaly etal, 2013) Other publications clarified the evolution of the term of cultural sustainability and its importance and applications (ICCPR, 2012) The cultural sustainability was discussed in many editions with applications in many countries via case studies (Chiu, 2004) (Hamansari, 2012) (Virtanen etal, 2012) (Zinas etal, 2010) (Turcotte etal, 2010). 


\section{Traditional Omani Residence as a Reflection of Environmental and Cultural Aspects}

The concept of tradition with reference to the Prince's School of Traditional Arts is both timeless and universal. The term "Tradition" has several meanings. However, tradition can be defined as, the customs and manners of a particular society which are handed down from one generation to the next (Aaazm, 2008). According to Hassan Fathy, one of the pioneers of sustainable architecture, traditional architecture has resulted through accumulated experience and time. Fathy stated that the development of traditional architecture has integrated climate, local materials and social cultural values (Abdul Majid' 2013).

The climate of Oman is marked by very hot summers, where the summer temperatures have been known to reach $50^{\circ} \mathrm{C}$. The winter climate is very agreeable (Al-Lawati, 2005). Climate has a certain highly observed effect on architectural forms. As the principle purpose of building is to change the microclimate, people everywhere have learned to interact with their climate and build houses that are more satisfactory in providing them with the microclimate that they need. In arid zones, where Oman lies, the people live under the blazing sun and excessive heat, they constructed houses with thick walls with very small openings to keep out hot air and sun glare. Wooden lattices fill larger opening to subdue the sun glare while allowing the breeze to pass through (figure 1). Selecting materials with high thermal insulation qualities, like mud brick, was another technique (Fathy,archive,unu.edu) In addition, structures are grouped together to provide shade and to create relatively cool microclimates (figure 2). (Costa \& Noble, 1982).

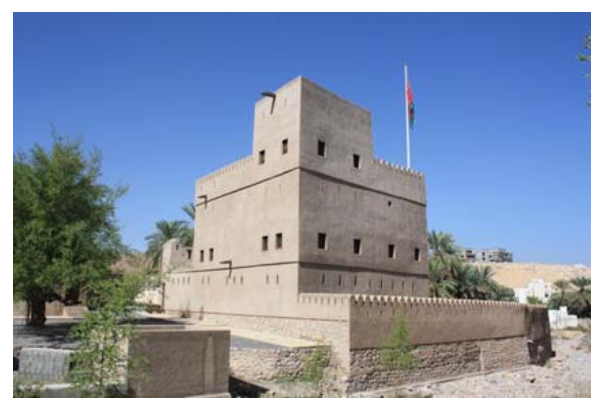

Figure 1. Traditional Omani houses with thick walls and very small screened openings.

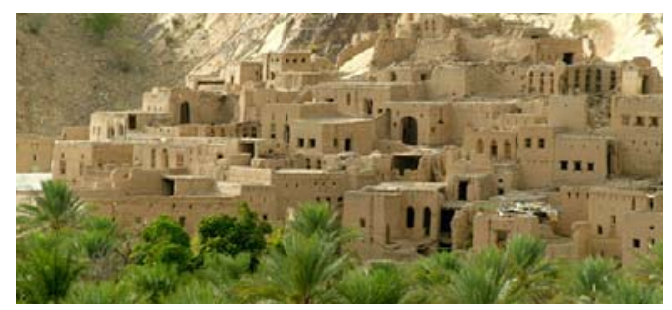

Figure 2. grouped structures to provide shade.

After having an in-depth look on the effect of environmental factors on Oman's architecture, another close look must focus on the culture of the Omani people.

There are many definitions of culture but in this study, two are noteworthy. The first one is by UNESCO in 1989; Cultural heritage is defined as "the entire corpus of material signs-either artistic or symbolic-handed on by the past to each culture and, therefore, to the whole human kind" (Axels son et.al, 2013). The other stated by Andretti and Ferrero in 1952 as "Everything that people have refers to material possessions; everything that people think refers to the things 
they carry around in their heads, such as ideas, values, and attitudes; and everything that people do refers to behavior patterns"(Scammon,www.academia.edu)

In the seventh century, Oman was one of the first countries to answer the call of Islam during the time of prophet Mohammed (PBUH)(AL Zubair, 2013). The religion of Islam penetrates into every aspect of man's life, leaving nothing untouched by the sacred. This means that there is no differentiation between the sacred and profane in the everyday life of a Muslim. The sharia that draws its inspiration from the divine law, regulates the daily life of the Muslim community by setting limits and guide lines that means all the ideas, values, and attitudes in the Muslim's head or his culture, affected by the limits and guide lines of his religion's believes of Islam (Azzam, 2008)

Nevertheless, basic Islamic design and decorative values are found in Oman's traditional architecture, conventions related to purity and simplicity that are in line with the Spartan life style enforced by the difficulties posed by Oman's climate, terrain and economical limitations that took expression in domestic architecture (Al Zubair, 2013). Art and architecture have always held a central role in the civilization of Islam. The art of architecture in Islam encompasses the full range of disciplines and crafts, like: carpentry, masonry, ceramic tile-work, metal work and stained glass. It is apparent that these arts and crafts exist to embellish and uplift the Muslim's everyday life. Some religious beliefs are affecting the Islamic architecture; the Muslim architect admits his submission to the divine will that God is the Supreme Architect. Thus, the relationship between the architect and his surrounding environment is one that is based on respect not arrogance. The Islamic art- namely, geometry biomorphic form or arabesque reflects the order of the universe. The arabesque or biomorphic, which symbolize pristine nature. The Muslim artist is inspired by the multiplicity of forms, patterns, and rhythms he sees around him in nature and abstract them to their fundamental essence (figure 3).

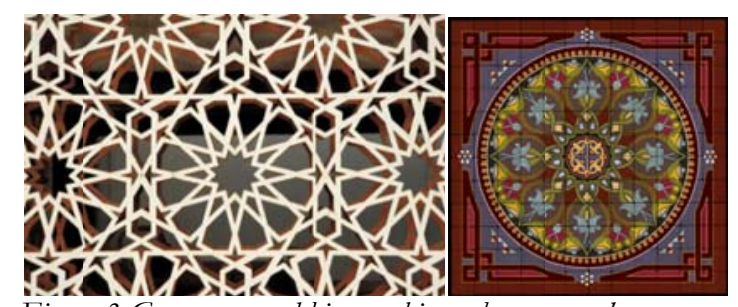

Figure 3 Geometry and biomorphic arabesque works

The fine and applied arts remain central elements in the everyday life of the Muslim, still practiced by craftsmen throughout the Islamic world (Azzam, 2008).

The culture of the Muslims and the Islamic way of life strictly stress privacy of a family and seclusion of females. Accordingly, the visual privacy was an essential element which affected the plan and the shape of all traditional Arab houses, to be clearly defined as public, semi public and private spaces. (El-shorbaggy, 2010). In the traditional Omani architecture, the main apparent principle which affects the house design relates to Islamic conventions of privacy. The introverted character of the dwelling, the arrangement and the orientation of rooms and viewing windows, towards the interior courtyard, the bent entrance (majas), the exterior screened windows and the combination of the covered interior courtyard and the wind catcher (malqaf) are all distinctive characteristics of the Omani house. All these features are representing the response to the needed high level of privacy.

Finally, it was obvious that every architectural element in the traditional Omani house, as the other traditional houses in the Arab world, represented a solution to a different problem that performed according to specific condition. There were a sequence of related challenges which were met successfully to achieve that beauty traditional house responded to certain 
environmental, social, cultural and religious mode and requirements.

\section{Adopting Contemporary Traditional Architecture, A state Policy}

Oman has existed as a district country as far back as the fourth century BC. Throughout its history, Oman experienced periods of prosperity interspersed with periods of relative calm. (McBrierty, 2003). In 1970, with the accession to the throne of his majesty Sultan Qaboos bin Said, the contemporary architecture of Oman commenced its Renaissance. The past four decades have been a period of unprecedented development, growth and prosperity for the Sultanate of Oman (Al Zubair, 2013). Major infra structural projects were realized.

Oman's renaissance included not only a comprehensive renewal of all aspects of the country's society and economy, but also a flowering of the arts and culture. Oman does not compromise traditions and social values. It is evident that Oman's deep rooted history is a source of national pride. In 1970, two architect Consultants, British and Iraqi, were each commissioned to prepare a planning proposal for the development and extension of the capital Muscat and neighboring Mutrah. The two reports had similar primary aims to determine the status and role of the old city of Muscat in the context of national politics and economics; to preserve the walls and traditional buildings in the new districts; and prepare plans for the expanding metropolitan region. Their reports emphasized the vast national value of Muscat's heritage that they recommended should be enriched by maintenance and renovation.

In 1980s, the Ministry of Land affairs based on the above mentioned studies issued guidelines that stipulated new buildings to comply with "Islamic Forms". These guidelines were developed in 1987; an "Elevation Guideline" was enacted by the Diwan of the Royal Court. This document aimed to ensure the high quality of architectural design in the new constructions with reference to the unique Arab/ Omani and Islamic architecture. The attached illustrations to the "Elevation Guideline" manual were restrictive. Sets of drawings specified the form and style of boundary gates and walls, main entry doors and windows giving a variety of options for arched or flat in lets, modifies and railing (Figure 4).

The manual succeeded in controlling the chaotic development that happened in a very speedy developing city. The next edition of "Building Regulations for Muscat" in 1992 allowed for creative designs with the frame of the local, Arabic and some Islamic architecture (Damlaji, 1999). Those regulations have been re-revised, evaluated and modified in 1992 and 2011.

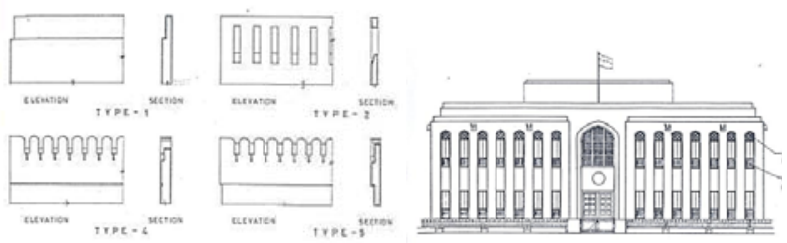

Figure 4. "Elevation Guideline" manual to control the elevations of new buildings (The Diwan of the Royal Court)

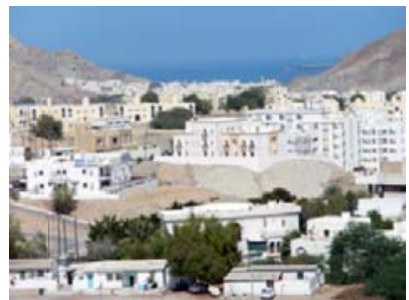

Figure 5. contemporary Omani architecture in line with the traditional one 
In all editions, the content of the following article was not changed "The architectural design of facades/elevations of residential and residential/commercial buildings shall be according to the local, Arabic, or Islamic style" (Building Regulations for Muscat, chapter 11, point2, article No.33). Other regulations in the building code were also enforced un precedented in the Gulf region, restricting height of buildings to a maximum of three stories for residential buildings. Certain light colors are also mandatory (Muscat Municipality publications, 1992). The above specifications retain the wonderfully sensitive appreciation of the natural environment of the contemporary Omani architecture as the traditional ones (figure 5).

\section{The Current Omani People Attitude of House Design}

A questionnaire was distributed, accompanied with interviews of an arbitrary sample of architects and consultant architects. The sample of six participants had a variety of experience working in Omani market (ranging between 4-24 years), different academic back ground (their degrees from United States, India, Egypt, and Palestine), and different gender is represented (three female and three male designers).In addition, the consultant offices are located in different districts in Muscat, The capital; Rawi, Al Wattia, Al Hail, Al Mwalhand Al Khoud.

Research objectives are to investigate the customer's general attitude of commitment to use the features of the traditional Omani architecture. In addition, identifying the most used traditional items and the common guidelines of requested design and plan morphology. The budget in guiding the application of traditional items was also included. Moreover, the increasing or decreasing trend of commitment to the heritage vocabulary between the old and young customers was also measured.

All the participants agreed that the budget limited the inherent wish of the customers to use the traditional vocabulary and enforce people to lower their satisfaction to the minimum. The prevailing traditional features in contemporary Omani architecture are respectively as shown in (Chart 1) are; arches, crenellation, domes, arabesque works, and mashrabiya. The ratio of using traditional elements between customers according to budgetary constraints is also include.

In addition, all the designers agreed that providing privacy is the common selection between all customers. All the customers asked to use tinted reflected glass for windows that obscure the vision. Other privacy elements like including two separate majlis (reception hall) for women and men is required with $80 \%$ of the customers and using bent entrance to the sitting area or two separate doors for guests \& family, is applied by $65 \%$ of the customer houses according to (Chart 2).

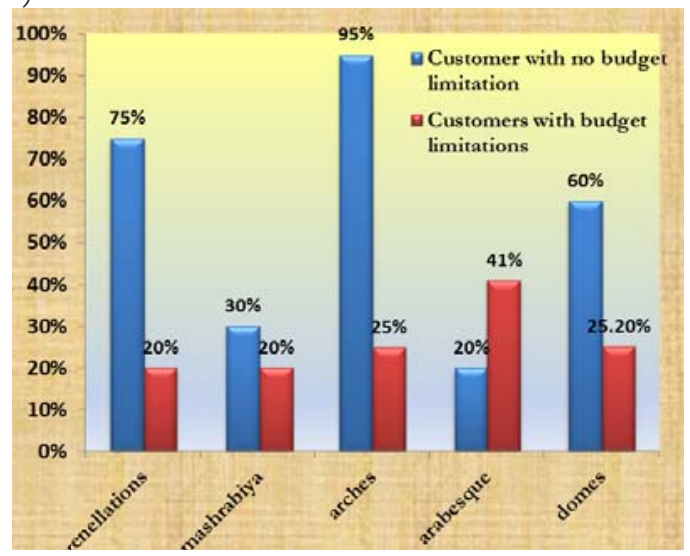

Chart 1. The prevailing traditional features in contemporary Omani architecture 


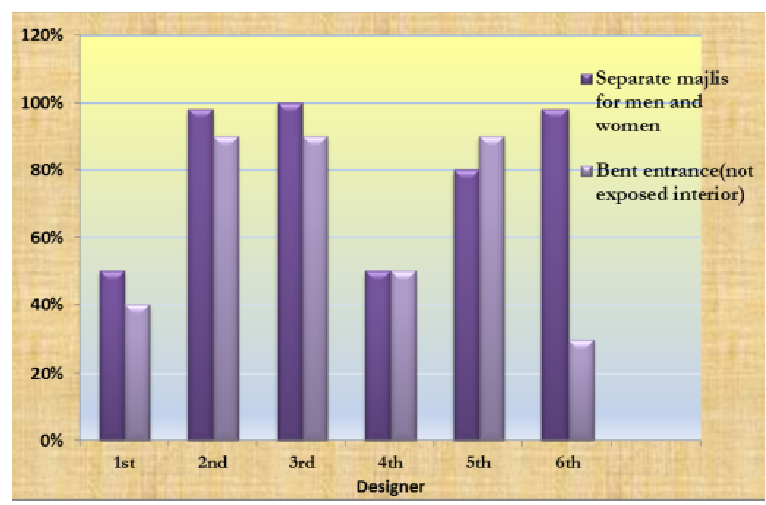

Chart 2. The ratio of including privacy elements in the contemporary Omani residences

The consultants agreed that the new generation of Omani people tend to prefer modern design The author conducted a survey of Omani people in 2010 and $79 \%$ of the participants preferred the traditional style.

\section{Cultural Continuity - Cross Case Studies Analysis}

The three projects identified for this study represent three centuries of time- frame to test the cultural sustainability. In addition, to avoid the effect of budgetary constraints, the three projects belong to owners with no economic limitations. Different locations in Oman are also targeted. The availability of information and documentation -especially for the historical examples- was one of the controlling factors.

This paper used multiple data and evidence-gathering techniques. Collecting documents of engineering drawings was the first technique. Interviewing the two owners of the two contemporary residences was the second one. Using questionnaire form filled by the owners to document the data gathering was also used. Direct observation through conducting visits for the three case studies was also employed. (Turcotte, 2010)

This paper will test the cultural continuity of some design criteria that accumulated in the sub conscious of the population over centuries (Elnokaly,2013). Respecting family privacy influenced the plan morphology and openings design (Al-Shorbaggy, 2010). The relationship between the constructions and surrounding environment at the level of height color and material. In addition, the using of geometry and biomorphic form or arabesque works and the use of Ogival and scalloped arch are some of heritage symbols that have evocative nature (Al-Zubair,2013).

The analysis of case study data using a pattern fitting approach evaluated to what extent these criteria are embodied in each residence and why were or were not reflected in each case. (Turcotte, 2010).

\subsection{House Moqham}

The House Moqham is a historical monument that is built in state Bucher. It was built by and lived in it during the twelfth century AH. (three centuries ago) The Ministry of Heritage and Culture restored and rehabilitated this house twice in 1991 and 2010 as a museum (www.adel14c.ala\&dal.net/t348).

The morphology of the house plan has three identified zones; public, semipublic and private the private zone of bedrooms isolated vertically on the first floor and grouped around open court yard with minimal out door screened openings. The construction of two story building in earthy color stone material and wooden roof is sensitively related to the surrounding environment. As 
Oman is a land of scarce resources and conservative values till the 1970s, the aesthetic value of using the craftwork of arabesque was restricted to the main entrance doors using ogival arch characterized by a beauty of proportion and elegance in interiors is shown in(figures 6)
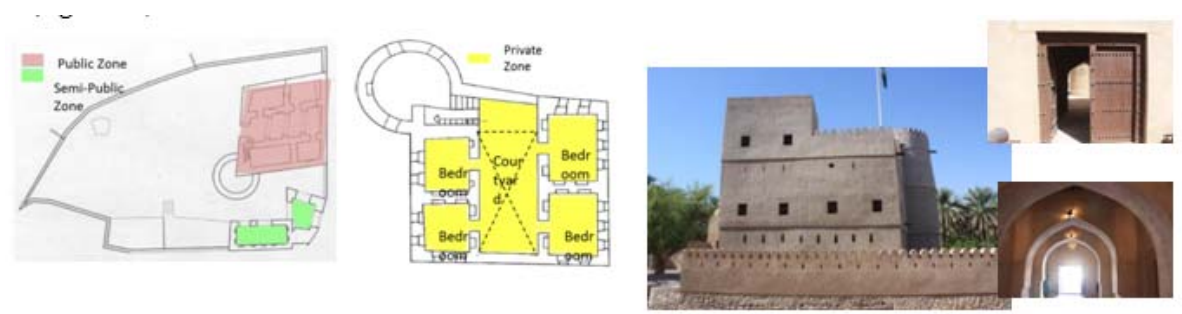

Figure 6. Public, semi-public and private zones and other architectural features

\subsection{Baital Dalalil}

Bait al Dalalil has a historic and cultural value, as it was erected at the early 1900s (one century ago). It was the first old Muscat house to be opened to the public it is original manifestation (Al Zubair, 2013). At the level of morphology, the plan has also three zones; public zone, semi-public zone and private zone Including three entrances one per each zone provided the required level of Privacy the tow entrances to private and semi-private zones are bent once facing a wall not a space. In addition, there is an open to ask interior courtyard at the semi-private zone with wind catches to achieve thermal comfort without depending on exterior openings which affected the family privacy. Later, the open courtyard was transformed into a covered gallery space with horizontal stained glass windows the construction of one story light color building, mud brick walls that are more than two-thirds of a meter thick and wooden roof is achieving sustainability with surrounding environment the aesthetic value of using the carved wooden doors and white-on white plaster arabesque motif works are more represented than the first case study moreover, using the same ogival arch besides the scalloped arch indicates continuity with first example three centuries ago (figure 7)
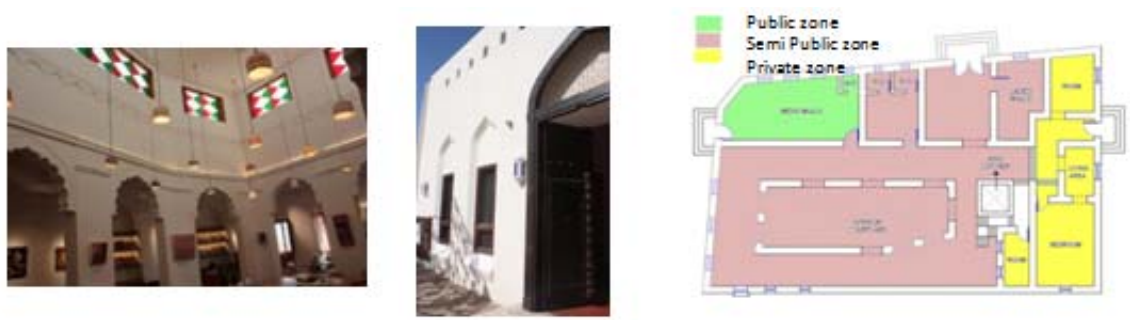

Figure 7. Public, semi-public and private zones and other architectural features

\subsection{House Omar Al Shanfri}

This house is erected in 2011 in Salalah, In spite of spending five years in United States to study computers science, Omar chose his house design completely in line with the traditional Omani architecture. The owner of this house has no economic limitations. All the inherent cultural values and beauty freely in the design with no constraints. The morphology of the plan is also divided into three obvious zones, the public, semipublic on the ground floor with separate entry for each zone(figure 14-a) the private zone of bedroom vertically on first floor.

The construction of two floor height and light colors to incorporate sensitively with the surrounding the arabesque work is excessively used in different materials (wood, gypsum and 
plastic) the continuity of using ogival and scalloped arches in the front elevation and interiors (figure 8).Going through the three case studies the cultural sustainability of Omani residences is highly represented.
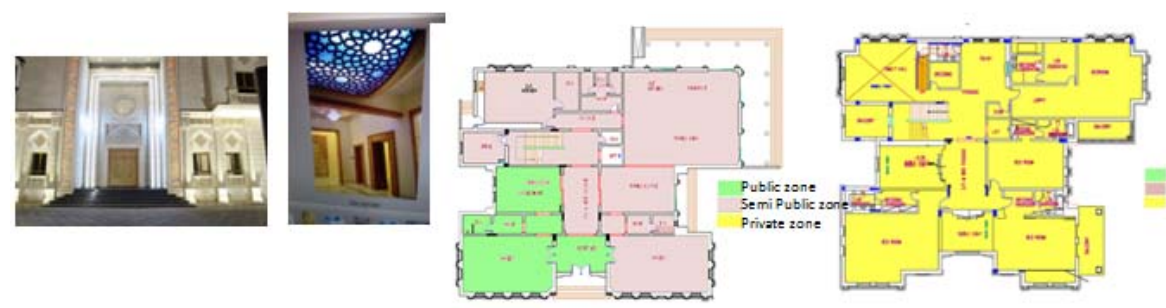

Figure 8. Public, semi-public and private zones and other architectural features

\section{Conclusions and Recommendations}

The traditional architecture in Oman came about through accumulated experience over a time frame which started from 4000 B.C. The development of such traditional architecture integrated climate, local materials and socio-culture.

Oman was one of the first countries to answer the call of Islam in the seventh century. The religion of Islam penetrates through every aspect of man's life, creating inherent symbolic language. There are certain limits and guidelines that regulate the daily life of the Muslim, which are reflected on his ideas, values and attitudes. The state policy in adopting contemporary traditional Omani architecture through many decisive legislations and regulations is further discussed. The current Omani people's attitudes to house design is clarified through the results of a questionnaire distributed to architect consultants. Subsequently, cultural continuity is revealed through the analysis of cross case studies of three residence examples that have been erected within a time frame of three centuries.

The recommendation of this work is as follows: the applications of the traditional Omani ideas in contemporary buildings are suggested as a means to reduce energy consumption. This issue however needs further research. The awareness of the importance of traditional Omani architecture is promoted by education, communication, and public policies. The new generation of Omani people showed less interest in the continuity issue, as they value buildings that define elements of their cultural identity. Each community has to seek improving people's quality of life through promoting and protecting the cultural sustainability of the society. Deriving lessons from the Omani experience in keeping the continuity between its heritage and contemporary architecture is advisable. Local policies have a crucial role in the protection of the community's culture. Finally, cultural sustainability which affect people's satisfaction and the state's identity should be included in any state policy and also be a part of all decisions and actions on the local and national levels.

\section{References}

Abdul Majid, Noor, et al (2013) cultural and Climatic Analysis: The Basis of Formulation Compatible living Environments in Oman, Asian Journal of Environments -Behavior studies, volume 4 Number 13, May/June 2013.

Al Lawati, Nadia (2005) The Omani House Domestic Space: between traditional and Modernity, Mankitosh School of Architecture. P.11, 8 
Axelsson, R., Anglestan, P., Degerman, E., \& Teitelbum, S. (2013) social and cultural sustainability: criteria, Indicators, verifier Variables for Measurement and Maps for Visualization to Support Paining, AMBio, 42:215-288. Springrelink.com p. 215, 217

Al Zubair, Mohammed (2013)Oman's traditional Journey; BAZ publishing, Sultanate of Oman. P.26-40, 370

Azzam, Khalid seen in Adam, Robert (2008)Tradition today-continuity in Architecture \& society, WIT press, Boston. P. $95-102$

Culture of Oman- History, people, clothing, traditions, Retrieved from: www.everyculture.om, Damluji, Salma Samar (1998) The Architecture of Oman, UK. P. 58-61

Fathy, Hassan, "Natural Energy and vernacular Architecture: Principles and Examples to Hot Climates; Library of Congress Cataloging-in-Publication p. 9,26-40, 370 -retrieved from data,.archive.unu.edu/unupress/unupbooks/80a01e/80A01E00.htm,

El nokaly, Amira, Elseragy, Ahmed (2013) Sustainable Heritage Development: Learning from Urban Conservation of Heritage projects in Nonwestern contexts, European Journal of sustainable Development (2013), 2,31-54, ISSIV: 2239-5938. P.31 - 54, vii

El-shortage, Abd Almoniem(2010)"Traditional Islamic-Arab House: Vocabulary. And syntax, International Journal of Civil \& Environmental Engineering IJCEE-IJENS VOl:10 No:04. P15-17

International Conference on Cultural Policy Research, Culture, Polices and Cultural Policies (2012) Investigating Culture, Cultural Policy, and Sustainable Development, Barcelona.

Scannom, Denise (2015) Sustainability and Culture How do they work together Retrieved from, www.acodemia.edu,

Turcotte, David A and Geiser, Ken (2010) A Framework to Guide Sustainable Housing Development, Journal of the Housing Education and Research Association, Housing and Society, 37c2,p.87-112

Virtanen, Pirjo K. and Sarrien S. (2012) How to integrate Socio-Cultural Dimensions into Sustainable Development: Amazonian case studies, Int.J. Sustainable Society, Vol.4 No. 